\title{
CONDIÇÕES FILOSÓFICAS PARA UMA ESTÉTICA HUSSERLIANA
}

\author{
Luciane Luisa Lindenmeyer ${ }^{1}$ \\ Universidade do Vale do Rio dos Sinos (UNISINOS) \\ https://orcid.org/0000-0002-6386-9171 \\ E-mail: lucianelindenmeyer@gmail.com
}

\section{RESUMO:}

Este artigo apresenta as condições filosóficas para o estabelecimento de uma estética especificamente husserliana. Para tanto, são primeiramente consideradas as equivalências filosóficas entre duas modalidades de experiência consciente: a fenomenológica e a estética. Por conseguinte, destacamos alguns dos conceitos que norteiam a fenomenologia husserliana como percepção, experiência intuitiva, imaginação e consciência de imagem. Apresentamos uma aproximação conceitual entre a experiência fenomenológica, como experiência de consciência imediata que tem na percepção o caminho privilegiado para o acesso aos dados originários dos objetos intencionais. A experiência estética, enquanto tipo específico de percepção e sensação, converte-se em uma modalidade de experiência fenomenológica, na medida em que integra, em si mesma, sujeito e objeto em uma relação propriamente intencional funcionando como um perfeito paradigma da atitude perceptiva fenomenológica contraposta ao modelo de experiência naturalizada. Tanto a estética quanto a fenomenologia possibilitam a centralização da experiência consciente como relação consciência-mundo, muito mais do que a caracterização objetiva do mundo ou de quaisquer fatos puramente psicológicos. Em ambos os campos filosóficos a imaginação possui um status de destaque.

PAlaVRaS-CHAVE: Fenomenologia; Estética; Experiência; Percepção.

\section{PHILOSOPHICAL CONDITIONS FOR A HUSSERLIAN AESTHETIC}

\begin{abstract}
:
This paper presents philosophical conditions for the foundation of a specifically Husserlian aesthetic. Therefore, will be at first considered philosophical equivalences of two modalities of conscious experience: phenomenological and aesthetic. Thereafter, we highlight some of the concepts that guide Husserlian phenomenology as perception, intuitive experience, imagination and image consciousness. We present a conceptual approach of phenomenological experience as an experience of immediate awareness that has in perception the privileged path to access data originating from intentional objects. Aesthetics experience as a specific type of perception and loss, becomes a modality of phenomenological experience, insofar as it integrates, in itself, the same subject and object in a relationship properly intentional experience, functioning as a perfect paradigm of phenomenological perception opposed to naturalized experience model. Both aesthetics and phenomenology make it possible to centralize conscious experience in relation to world-consciousness, much more than the objective characterization of the world or any purely psychological facts. In both philosophical fields, imagination has a prominent status.
\end{abstract}

KEYWORDS: Phenomenology; Aesthetics; Experience; Perception.

\footnotetext{
${ }^{1}$ Doutorando(a) em Filosofia na Universidade do Vale do Rio dos Sinos (UNISINOS), São Leopoldo - RS, Brasil. Bolsista do(a): Coordenação de Aperfeiçoamento de Pessoal de Nível Superior ( CAPES), Brasil.
}

LINDENMEYER, Luciane Luísa. Condições filosóficas para uma estética husserliana. Griot : Revista de Filosofia, Amargosa BA, v.21 n.3, p.197-217, outubro, 2021. 


\section{Introdução}

Podemos iniciar a aproximação conceitual da estética com a fenomenologia com base na reconstituição de alguns dos elementos contidos nas origens do processo de emancipação da estética, enquanto disciplina específica, e nas formulações filosóficas que influenciaram diretamente a fundação da fenomenologia husserliana. Tanto a estética, tal como formulada a partir do século XVIII, quanto a fenomenologia possuem influências do pensamento cartesiano na constituição de seus projetos originários.

A primeira disciplina filosófica citada começou a ser esboçada, anteriormente à formulação teórica de Alexander Baumgarten, não apenas no campo de desenvolvimento histórico que resultou na passagem da Idade Média para a Renascença, virada cultural muito significativa para a emancipação da arte em relação às suas atribuições religiosas, como também no campo filosófico a partir da formulação do cogito cartesiano e da centralização do problema do conhecimento no sujeito pensante até o momento de elaboração posterior da abordagem da experiência estética especificamente kantiana.

A segunda disciplina mencionada está diretamente vinculada ao modelo de pensamento radical postulado por René Descartes, a partir do qual Husserl aborda o grande problema da possibilidade de apreensão do transcendente, isto é, daquilo o que está fora da consciência transcendental. Da mesma maneira, ele pretende fundamentar a sua teoria do conhecimento de modo semelhante ao modelo cartesiano, racionalista e universalizante. Apesar de divergências em relação ao projeto transcendental de Descartes, Husserl mostra-se como um cartesiano também ao considerar a mesma distinção entre percepção e sensação já formulada por Descartes, no sentido de que

[...] o verbo "perceber" (em latim, percipere), para Descartes, não se refere de maneira exclusiva a processos ou atividades dos sentidos. Quando quer falar das sensações, Descartes emprega o verbo "sentir" (em latim, sentire). O termo "perceber" é preferencialmente utilizado para designar um ato puramente mental do intelecto (ou entendimento). A percepção é intelectual. (SAES, 2010, p.16).

É claro que o projeto teórico husserliano demarca as distinções entre experiência perceptiva (Erfahung), vinculada à experiência intuitiva imediata, e a imaginação, por exemplo, sendo essa um dos atos intencionais de cunho intelectual que compõem a experiência fenomenológica. No entanto, essas duas concepções estão mutuamente vinculadas, o que resulta em uma visão de percepção ainda correspondente a atributos intelectuais. Muito embora essa relação não anule o primado da percepção como experiência originária, uma vez que os atos intelectuais contribuem para a apreensão das idealidades ou dos significados dos objetos intencionais.

O ponto inicial aqui é a aproximação entre estética e fenomenologia justamente com base na noção de percepção, elemento crucial para ambas as disciplinas e com a qual podemos pensar em como ocorre a percepção que caracteriza a experiência propriamente estética. Para iniciarmos essa empreitada partimos da definição de que

A palavra "estética" vem do grego aísthesis, que significa sensação, sentimento. Diferentemente da poética, que já parte de gêneros artísticos constituídos. A estética analisa o complexo das sensações e dos sentimentos, investiga sua integração nas atividades físicas e mentais do homem, debruçando-se sobre as produções (artísticas ou 
não) da sensibilidade, com o fim de determinar as suas relações com o conhecimento. (ROSENFIELD, 2006, p.6).

A influência conceitual da fenomenologia para a estética é constatável no que se refere ao seu paradigma de análise que se reverte na atitude fenomenológica, isto é, na atitude que pressupõe a unificação do objetivismo e do subjetivismo. A consciência não é separada da realidade e o sujeito recupera a sua posição de centralidade cartesiana na constituição do conhecimento, mas com uma nova condição: a de intencionalidade, onde há a constante vinculação direta da consciência com toda a realidade transcendente, de modo que "Como estrutura dos próprios comportamentos, a intencionalidade é uma estrutura do sujeito que se comporta. Sob o modo de ser do sujeito que se comporta, ela é o caráter relacional dessa relação". (HEIDEGGER, 2012, p. 94).

Ao considerarmos o projeto teórico legado pela fenomenologia, é possível pensarmos nos problemas filosóficos tendo em vista a possibilidade de partirmos da irrefutabilidade das essências eidéticas fenomênicas que aparecem para a consciência de forma direcionada para os problemas concretos, às "coisas mesmas"2, a partir das quais conhecemos não os fatos, mas os elementos gerais, as essências, daquilo o que está sob análise da intuição eidética e da epoché husserlianas. A experiência fenomenológica e os seus preceitos intuitivos de análise permitem a aproximação teórica entre a fenomenologia e a estética. Desse modo, é possível considerarmos que a experiência estética é equivalente à experiência fenomenológica, no sentido de que

A experiência estética encontra o que procura no nível da aparência; por exemplo, encontra a qualidade da tristeza na melodia ou poema em si. É também por isso que o conhecimento por familiaridade [connaissance] é, a todo momento e para cada assunto, completa na experiência estética. Quando aprendemos a ver algo novo em uma melodia ou poema, isso não é progresso, mas conversão ${ }^{3}$. (DUFRENNE, 1973, p. 432).

O desenvolvimento teórico da fenomenologia husserliana é composto por conceitos que adquiriram ressignificações a fim de que eles façam sentido na totalidade de sua proposta filosófica. Um desses termos específicos é o próprio conceito de experiência. Seria um contrassenso adotarmos a concepção clássica de experiência quando parte da fundamentação teórica para uma defesa da fenomenologia enquanto campo autônomo passa pela crítica ao positivismo e ao naturalismo, na medida em que,

Naturalismo tenta explicar princípios lógicos inteiramente em termos de psicologia: princípios lógicos são princípios psicológicos; as leis da lógica são leis naturais da psicologia, ou seja, leis que generalizam como entes humanos e talvez outros entes sencientes pensam. (CERBONE, 2012, p. 21).

Consequentemente, a experiência fenomenológica, enquanto análise pré-científica, não corresponde aos métodos de análise que reduzem os seus procedimentos à busca pelo conhecimento objetivo por meio da dissecação cientificista. A orientação intencional da análise

\footnotetext{
2 Ao contrário do que uma primeira leitura possa sugerir, no contexto da teoria fenomenológica, as coisas mesmas não correspondem aos fatos empíricos, mas sim às essências (eidos), uma vez que a pretensão de Husserl em formular uma teoria rigorosa deve corresponder a fundamentos que são apriorísticos e não contingentes. Nesse sentido, as essências captadas por meio da percepção dos fenômenos não podem ser reduzidas unicamente à empiria.

3 Tradução minha (Cf. DUFRENNE, 1973, p. 432): “Aesthetic experience finds what it seeks on the level of appearance; for example, it finds the quality of sadness in the melody or poem itself. This is also why knowledge by acquaintance [connaissance] is, at every moment and for every subject, complete in the aesthetic experience. When we learn to see something new in a melody or a poem, this is not progress but conversion".
}

LINDENMEYER, Luciane Luísa. Condições filosóficas para uma estética husserliana. Griot : Revista de Filosofia, Amargosa BA, v.21 n.3, p.197-217, outubro, 2021. 
fenomenológica está direcionada para as necessidades eidéticas, sendo elas mesmas uma modalidade de consciência. Assim,

O nexo (ele mesmo eidético) que ocorre entre objeto individual e essência, segundo o qual cada objeto individual tem uma composição eidética como sua essência, assim como, inversamente, a cada essência correspondem indivíduos possíveis que seriam suas singularizações fáticas, funda uma referência recíproca correspondente entre ciências de fato e ciências de essência. (HUSSERL, 2006, § 7.p. 42).

A experiência fenomenológica, longe de ser uma modalidade de experimento, refere-se a todas as vivências da consciência intencional, ou ainda, ao conteúdo dessa consciência, a partir dos quais podemos falar de uma evidência fenomenológica. Nessa conformidade, a vivência fenomenológica é tida como "[...] efetividade, como consciência que apreende ou põe existência". (HUSSERL, 2006, § 7. p. 42). Ao partirmos das proposições da fenomenologia husserliana para pensarmos nas questões específicas da estética, podemos considerar os temas que ultrapassam a esfera do campo próprio do artístico para nos movermos em direção ao conteúdo rigorosamente metafísico que abarca as próprias condições de apreensão dos objetos estéticos.

\section{Experiência estética como experiência intencional}

É claro que é parte indissociável da constituição da análise estética dos objetos a sua dependência direta dos dados da percepção sensitiva, da intuição e da imaginação. No entanto, há um outro caminho de aproximação teórica da fenomenologia com a estética que está relacionado com a fundação de uma postura intermediária entre o objetivismo e o subjetivismo, de maneira que "temos de agradecer, antes de mais nada, à crítica fenomenológica aplicada à psicologia e à teoria do conhecimento do séc. XIX a liberação dos conceitos que impediam uma adequada compreensão do ser estético". (GADAMER, 1997, p. 105). Ora, aqui Gadamer só pode estar se referindo à fenomenologia de Edmund Husserl, seja por conta do período histórico pontuado, seja porque as críticas indicadas por Gadamer são fundacionais para a fenomenologia como campo filosófico. Muito embora, a estética propriamente fenomenológica só tenha sido de fato tematizada e aprofundada por autores posteriores a Husserl. Nesse sentido, essa afirmação gadameriana nos instiga a aprofundar em que medida podemos pensar a mencionada "liberação" das questões estéticas através da fenomenologia husserliana.

A crítica ao psicologismo e ao naturalismo situam a posição fenomenológica como sendo intermediária entre objetivismo e subjetivismo. A nova configuração de experiência que daí se segue corresponde à própria condição de intencionalidade a que estão submetidos a consciência transcendental e os objetos transcendentes. É justamente por meio da condição intencional da consciência que a análise fenomenológica é incompatível com a análise puramente psicológica, no que se refere à sua pretensão de estabelecer uma ciência rigorosa, de modo que

[...] A psicologia, considerada como ciência de certos fatos humanos, não poderia ser um começo, porque os fatos psíquicos com os quais nos deparamos nunca são primeiros. Eles são, em sua estrutura essencial, reações do homem contra o mundo; portanto, supõem o homem e o mundo, e só podem adquirir seu sentido verdadeiro se inicialmente elucidamos essas duas noções. (SARTRE, 2009, p. 21). 
No contexto de uma proposta de realismo direto ${ }^{4}$, devido à rejeição do conhecimento enquanto representação, a fenomenologia husserliana não se refere ao objeto especificamente científico. Sua constituição crítica é fundada pela análise de possibilidade do conhecimento objetivo que implica diretamente o sujeito consciente. Suas demarcações teóricas estão ligadas à distinção entre duas orientações: aquela concernente à atitude natural, que está vinculada ao objeto puro e sem vínculo qualquer com a subjetividade, objeto que aparece na teoria de Husserl como sendo tudo aquilo que é transcendente, que está fora da consciência e que, por isso, é indistinto e está suspenso da análise fenomenológica. A outra orientação é a atitude fenomenológica ou transcendental, que se refere ao objeto propriamente intencional, que sempre depende da consciência subjetiva por meio de uma relação mútua e indissociável. É justamente nessa última perspectiva, a fenomenológica, que podemos pensar nas questões específicas da estética, isto é, parece ser condição característica e inseparável do objeto artístico que ele sempre se apresente para a subjetividade na sua dimensão fenomenológica, isto é, o objeto artístico não equivale a um objeto puro a ser dissecado empiricamente.

A estética, por sua vez, no que se refere a sua proximidade com a teoria e a história da arte, recorre ao uso dos diversos e variados estilos artístico, não sem, contudo, enfrentar problemas de sustentação, de modo que,

[...] faz pesar sobre quem quer que reflita sobre a arte e sobre suas obras o risco do fracasso. Ou o filósofo se entrega à especulação abstrata, caso em que a arte enquanto prática concreta lhe é inacessível, ou então aplica à arte o resultado de suas meditações, mas cessa desde logo de ser filósofo e, se pretende continuar a sê-lo de qualquer maneira a arte lhe escapa. (JIMENEZ, 1999, p. 17-18).

A tarefa da estética é justamente trazer à tona os elementos essenciais para a percepção constitutiva dos objetos artísticos, tendo como base os problemas vinculados à percepção e a sensibilidade. No âmbito da fenomenologia, nenhuma experiência pode ser efetivada sem que nela já esteja pressuposta a noção de intencionalidade, isto é, da indissociabilidade existente entre consciência e o mundo circundante. A partir dessa condição, é importante considerarmos que a análise fenomenológica, nos moldes husserlianos, corresponde à averiguação da consciência de maneira semelhante ao solipsismo cartesiano, de modo que " [...] devo agora adquirir uma ciência de uma peculiaridade inaudita, pois que ela, produzida exclusivamente pela e na minha subjetividade transcendental, não deverá valer, pelo menos no início, também senão para esta: uma ciência solipístico-transcendental". (HUSSERL, 2003, p. 10).

No entanto, a constituição de uma ciência denominada por Husserl de Fenomenologia plena pressupõe um movimento em direção às coisas que não fora antes considerado por Descartes. O desenvolvimento intencional da consciência pode ser melhor compreendido com base na "Fenomenologia plena, à qual compete, obviamente, fazer o caminho ulterior do solipsismo transcendental para a intersubjetividade transcendental". (HUSSERL, 2003, p. 10). Assim, podemos tratar da dimensão pública da consciência intencional, considerando que "A obra dá publicamente a conhecer outra coisa, revela-nos outra coisa; ela é alegoria. À coisa fabricada reúne-se ainda, na obra de arte, algo de outro". (HEIDEGGER, 1977, p. 13).

Sob estas condições, o que está no cerne da análise fenomenológica não são os dados do objeto material que se manifesta enquanto fenômeno, mas sim as diferentes intencionalidades conscientes, isto é, a própria relação entre consciência e objeto enquanto estrutura que compõe o

\footnotetext{
4 Teoria contrária ao realismo epistemológico ou indireto, o qual corresponde à visão de que não é possível conhecermos o mundo como ele realmente é, mas apenas obtermos os dados capazes de serem captados por nossos sentidos.
} 
"caráter relacional a priori", (HEIDEGGER, 2012, p. 94), implícito em todo movimento intencional. A fenomenologia é fundamentada por um modelo de intencionalidade, onde a consciência é constituída por atos intencionais direcionados para a essência das coisas e que tem a intuição eidética como sendo o seu elemento central, por meio do qual a consciência tem acesso não unicamente ao ser constituinte de cada fenômeno, uma vez que esse procedimento filosófico deve tornar evidente a essência do objeto enquanto manifestação consciente.

A apreensão de essência possibilitada pela análise fenomenológica e que também é pressuposta na constituição de uma consciência especificamente estética, implica a temporalidade que caracteriza a consciência transcendental. Husserl considera que, nas suas Lições (Hua X), "Captar, e captar na verdade com evidência, um conteúdo tal como é vivido, tal não quer dizer ainda captar uma objectividade no sentido empírico", (HUSSERL, 1994, p. 41), para em seguida apresentar um exemplo de um pedaço de giz, a fim de afirmar que esse objeto será o mesmo, enquanto essência, se fecharmos os olhos após o visualizarmos. A modificação realizada no interior dessa experiência, dos conteúdos primários da sensação até a consciência da imagem mental que aparece quando fechamos os olhos, está no âmbito da temporalidade de cada ato de consciência. Isto significa que a percepção simples e imediata opera com base na sua própria condição temporal, assim como os demais atos da consciência imanente, como a imaginação e a recordação.

Com base nessas considerações, a proposta de desenvolvimento da aproximação teórica entre a fenomenologia husserliana e a estética parte tanto da análise da percepção e da sensibilidade, que correspondem ao fundamento próprio da estética, como também pelas vias em que tanto a fenomenologia, mesmo a de viés idealista de Husserl, quanto a estética podem resultar no estabelecimento de um conhecimento evidente e essencial. Portanto, a experiência estética e a experiência fenomenológicas são constituídas como experiências que evidenciam elementos duradouros e são também experiências de conhecimento.

O conhecimento explorado pela análise fenomenológica é aquele que permite a reflexão da própria experiência consciente, que é iniciada a partir da vivência perceptiva e imediata da consciência, até o momento da realização da análise intuitiva dos fenômenos, em nível transcendental. Esse conhecimento é o conhecimento de essência ou, o conhecimento eidético, e que só pode ser estabelecido após a redução fenomenológica, ou seja, após a passagem da atitude natural para a atitude fenomenológica. A experiência estética implica igualmente uma mudança de atitude pressuposta para a sua realização, de maneira que o objeto estético, ao ser tomado enquanto tal, efetiva o movimento de passagem de um objeto puro ou ordinário em direção ao status de objeto intencional, que é analisado na sua dimensão fenomenológica. Nesse sentido, ao considerarmos o objeto intencional, isto é, o objeto propriamente fenomenológico, "Este objeto (Gegenstand) é o que é visado nos vividos intencionais da consciência e não o que entra na consciência como se fosse, de facto, uma coisa". (ARAÚJO, 2011, p. 252).

No instante em que a arte se apresenta na sua dimensão fenomênica, a vivência consciente do seu conteúdo realiza-se no âmbito da subjetividade transcendental. É a partir da própria experiência da obra que a posterior depuração reflexiva e racional de sua forma deverá resultar no conhecimento eidético de seus atributos estéticos através dos modos de apresentação do próprio objeto.

\section{Condições fenomenológicas da experiência estética: entre a percepção e a imaginação}

A experiência estética é uma experiência fenomenológica na medida em que está direcionada para o que fica de duradouro na presença do objeto, a partir dos seus modos próprios de manifestação. No entanto, a análise fenomenológica permite igualmente que a experiência se

LINDENMEYER, Luciane Luísa. Condições filosóficas para uma estética husserliana. Griot : Revista de Filosofia, Amargosa BA, v.21 n.3, p.197-217, outubro, 2021. 
realize também por meio do que está ausente, do conteúdo não explicitado na obra, mas que aparece intuitivamente para a consciência intencional, de tal maneira que há um movimento alternado entre presença e ausência. Entre o que é dado pelo objeto correlato de modo manifesto e o que é apenas indicado pelas suas formas estéticas. Em todo esse processo intencional, a experiência natural está suspensa, em razão de que a análise fenomenológica sempre ocorre no plano transcendental e não há qualquer pretensão explicativa, que esgote o conteúdo do objeto, mas sim descritiva de seus fenômenos, enquanto vivências puras. Como vivência pura, a experiência estética ocorre na medida em que os modos de doação do objeto estético aparecem para a consciência intuitivamente.

São as vivências intencionais dos atos de consciência que permitem a realização do projeto fenomenológico enquanto possibilidade de estabelecimento de significações das "coisas mesmas", isto é, das essências dos fenômenos, tendo sempre como horizonte a orientação fenomenológica, por meio da qual a fenomenologia equivale à análise crítica da própria razão. A análise fenomenológica só acontece por meio do exame de cada uma das vivências de consciência enquanto atos intencionais. Esse exame é, na verdade, uma suspensão de todo e qualquer juízo que se mantenha indistinto enquanto a análise propriamente transcendental proceda. Ao pensarmos numa experiência fenomenológica, faz-se necessário considerarmos em que consistem as suas proposições, ou seja, a análise fenomenológica corresponde à análise das diferentes intencionalidades da consciência. Os atos intencionais estão diretamente vinculados às vivências conscientes. Por isso, a experiência é, aqui, equivalente ao que Husserl chamou de vivência intencional da consciência.

A vivência intencional sempre corresponde a uma experiência de consciência que resulta, após o procedimento das reduções fenomenológica e eidética, na instauração da evidência eidética, que equivale ao momento de instauração da clareza intelectual em relação ao objeto intencional. Nessa etapa podemos considerar tanto a efetivação de significados dos fenômenos quanto a apropriação do ser dos objetos, que se manifesta na sua condição eidética. Como já sabemos, esse procedimento de análise, pretende fundamentar uma teoria do conhecimento, mas suas proposições, como buscamos defender aqui, são plenamente aplicáveis ao contexto da análise estética. A vivência fenomenológica corresponde ao momento de superação da percepção dos dados imediatos do fenômeno pelo estágio de significação intuitiva. Isso significa que os dados perceptivos correspondem ao primeiro momento intencional, no qual ainda não podemos tratar de uma evidência intelectual absoluta, em razão de que a primeira manifestação do fenômeno para a consciência precisa passar pela redução eidética. É nesse momento que a intuição se torna o elemento indispensável para a depuração racional do objeto intencional.

A experiência estética implica a experiência fenomenológica na medida em que a sua efetivação ocorre pelas vias da intencionalidade e, num segundo momento, o sujeito que pretende interagir de maneira efetiva com uma obra de arte, seja ela um texto literário ou uma pintura, fará uso de suas capacidades intuitivas, nos moldes implícitos no contexto que é precondição para a atitude fenomenológica. Nesse sentido, as condições para a efetividade da experiência estética são as mesmas exigidas para a experiência fenomenológica, de modo que se faz necessária a mudança de orientação ou de atitude em relação ao objeto artístico enquanto fenômeno. A atitude natural é superada pela atitude fenomenológica quando a obra de arte não é tomada como um objeto natural ou ordinário, mas sim como um objeto que se apresenta na sua dimensão fenomênica, a qual está diretamente vinculada ao exercício transcendental que é realizado, num segundo momento, pela consciência intencional.

A obra de arte converte-se no objeto intencional, isto é, naquele objeto que não pode ser considerado sem as influências da subjetividade consciente ou transcendental. A obra de arte 
possui, por sua própria natureza de ser, um conteúdo que é inesgotável e que não é redutível à análise objetificadora como aquela aplicada aos objetos puros. Ao tratar das diferentes atitudes que compõem a análise fenomenológica, como já mencionadas, a natural e a transcendental ou fenomenológica, Husserl não pretendia enaltecer as distinções entre arte e ciência. Já que a fenomenologia enquanto ciência radical está relacionada com a análise de todo o mundo circundante em relação à consciência intencional. Husserl visa a estabelecer as bases para a fundamentação da sua "nova modalidade" de conhecimento, qual seja, o conhecimento eidético. Isso quer dizer que o conhecimento resultante da análise fenomenológica não deve corresponder àquele relativo às ciências positivas, já que parte da refutação husserliana ao método científico ocorre justamente porque as suas próprias concepções fenomenológicas redutivas não visam ao mesmo objeto e tampouco pretendem explicar a realidade, mas sim descrevê-la conforme a sua constituição intencional.

É preciso assinalar que, uma vez realizada a suspensão da atitude natural, não podemos incorrer em uma atitude judicativa, atribuindo valores, mesmo estéticos, aos objetos. Segundo afirmação do próprio Husserl (2006, §56 p. 131):

É óbvio, em primeiro lugar, que, com o mundo natural, tanto físico como psicofísico, posto fora de circuito, também estão excluídas todas as objetividades individuais que se constituem mediante funções valorativas e fáticas da consciência, todas as espécies de realizações da civilização, obras das artes técnicas e das belas-artes, das ciências (consideradas não enquanto unidades de validação, mas justamente enquanto fatos de civilização), e toda forma de valores estéticos e práticos.

O que está em questão aqui é, sobretudo, como é constituída a experiência fenomenológica específica de objetos estéticos. Husserl tratou de uma consciência propriamente estética, em grande medida vinculada à sua teoria do conhecimento, em especial a partir da noção de imaginação, de modo que "as livres imaginações conseguem uma posição privilegiada em relação às percepç̃̃es" (HUSSERL, 2006, $§ 70$, p. 153). O objeto fenomenológico é tudo aquilo o que aparece para a consciência intencional, até porque sua proposta não visava a "servir a uma explicitação de objetos e não pretenderá imiscuir a filosofia nas tarefas dos saberes "positivos". (MOURA, 1989, p. 22). Consequentemente, o objeto fenomenológico é sempre um correlato e está situado no âmbito da orientação intencional da consciência. Como ciência de essências a fenomenologia terá a imaginação como ato de consciência excepcional. Assim como a estética.

É com base em afirmações como a de que "O domínio da fenomenologia é coextensivo ao de todas as ciências, já que ela abarca a totalidade dos fenômenos", (MOURA, 1989, p. 22), que tratamos da articulação entre fenomenologia e estética, através da formulação husserliana. Aqui, propomos inclusive uma reconstituição das bases da própria estética fenomenológica ${ }^{5}$ como disciplina filosófica. Desse modo, é a partir dessas questões chave do pensamento de Husserl que podemos pensar nas possíveis aplicações do seu projeto filosófico para a compreensão da experiência estética, enquanto experiência propriamente fenomenológica.

As origens conceituais da fenomenologia, enquanto teoria do conhecimento, remontam a um paradigma de experiência que visa a analisar, em regime transcendental, a própria condição de correlação entre consciência e objeto. Essa é uma das singularidades filosóficas que Husserl pretendia apresentar com a sua teoria dos fenômenos, uma vez que os projetos conceituais que precedem a fenomenologia na linha histórica da filosofia tendem a isolar cada um desses

\footnotetext{
${ }_{5}^{5}$ A estética fenomenológica é, de forma recorrente, atribuída à tradição fenomenológica francesa, tendo como grandes expoentes autores que aprofundaram o tema da fenomenologia da experiência estética, como Maurice Merleau-Ponty e Mikel Dufrenne. Ainda porque, de fato, Husserl esteve principalmente interessado em questões epistemológicas e, mesmo, gnosiológicas.
} 
elementos: a consciência em relação ao ser daquilo o que é transcendente e o ser transcendente em relação à sua aparência.

Como vimos, essas dicotomias consciência-mundo e ser-aparência são superadas no interior da fenomenologia por meio da concepção de intencionalidade, de forma que ela caracteriza tanto o que é transcendental, o que é consciente, quanto o que é transcendente, o que corresponde a tudo o que se manifesta para a consciência. Esses elementos implicam a não dissociação entre sujeito e objeto. $O$ mundo existe, mas ele recebe a todo momento o seu significado devido a sua relação direta e condicional com a consciência intencional. É através dessa estrutura relacional entre consciência e objeto intencional, que podemos pensar no ponto fundamental da análise fenomenológica acerca do conteúdo dessa modalidade de experiência, isto é, do objeto propriamente intencional, o qual está integrado aos atos de consciência, mas que não é, em si, o objeto real da experiência ou a coisa mesma.

A partir da crítica husserliana ao positivismo e ao psicologismo, tendo em vista as condições de estabelecimento de um conhecimento seguro, é realizada a fundamentação da análise fenomenológica por meio das capacidades intuitivas da consciência, como o próprio Husserl propõe,

Fazer do conhecimento um dado evidente em si mesmo e querer aí intuir a essência da efectuação não significa deduzir, induzir, calcular, etc., não significa inferir novas coisas com fundamento a partir de coisas já dadas ou que valem como dadas. (HUSSERL, 2000, p. 26).

Nesse sentido, tanto a indução, como método da análise dos objetos naturais particulares e a dedução, enquanto formulação da própria teoria científica, estão comprometidas com um método de análise que visa a explicar a realidade, de modo que a fenomenologia encontra no método intuitivo as condições apropriadas para que a experiência fenomenológica seja uma experiência descritiva, e, como vimos, não explicativa, já que seu projeto não é sequer direcionado para os objetos puros, que necessitam da mediação científica, mas sua reflexão está voltada para a própria vivência perceptiva, intuitiva e imaginativa da consciência. Acerca do uso da noção de imaginação em um projeto filosófico fundado principalmente como teoria do conhecimento é preciso destacar que

\footnotetext{
Na obra de Husserl, as análises da consciência de imagem e imaginação passaram por diversas elaborações, indiciando uma certa necessidade do autor em reexaminar tal tema sob perspectivas diferenciadas. Se, num primeiro momento, Husserl buscava desvendar as implicações gnosiológicas dos atos de imaginação, num segundo momento, este tema configurou-se como campo de investigação próprio e se estendeu ao domínio estético da fenomenologia da imagem. (SERRA, 2014, p.27).
}

Enquanto a imaginação prevalece como um elemento central para a apreensão consciente das essências, a percepção é relacionada com a presentificações, ou seja, com a presença da coisa ela mesma. É precisamente nesse sentido que ela será determinante para as vivências de consciência, pois que ela permanecerá como a condição para a originariedade dos dados das experiências. Percepção e imaginação atuam de maneira sincronizada e essa será a caracterização perfeita tanto para a experiência fenomenológica, claro, quanto para a experiência estética.

Por outro lado, é possível que uma rápida e superficial consideração sobre a experiência estética incorra na ideia de que tratamos apenas de elementos relativos quando pensamos na efetivação da relação do sujeito com a obra, isto é, de que a experiência estética corresponde àquilo o que cada indivíduo percebe no conteúdo artístico do objeto contemplado. Não seria possível, 
assim, considerarmos o estudo do que caracteriza a experiência estética por ela mesma, já que não há uma, mas várias experiências estéticas. São diversas as razões que impossibilitam essa visão da experiência estética através da abordagem fenomenológica. Primeiramente, recordemos que as origens do método fenomenológico partem do abandono do subjetivismo tradicional e solipsista para a adoção de um subjetivismo transcendental, que não depende da dualidade que opõe o sujeito e o objeto, pois que ainda que os atos intencionais conscientes estejam direcionados para o transcendente, "[...] a intenção não pode fazer nada sem uma base sensorial. $O$ ato surge da fusão destes dois elementos, intenção e sensação"6. (SARAIVA, 1970, p. 35).

A partir da aplicação dos preceitos da fenomenologia husserliana para a análise estética das obras de arte é possível pensarmos que a experiência estética se realiza também como uma modalidade de conhecimento eidético, ou seja, a arte apresenta-se como fenômeno por meio da redução fenomenológica para em seguida alcançarmos um elemento essencial para a sua constituição como sendo um objeto propriamente estético. Para tanto, a sua essência só será possível através da efetivação da redução eidética. Mas a que tipo de conhecimento estamos nos referindo aqui? Certamente ele não está na mesma relação hierárquica e de inferioridade em relação ao conhecimento científico como proposto por Baumgarten, na sua obra fundante da estética como campo de conhecimento autônomo, de forma que,

A ciência do modo do conhecimento e da exposição sensível é a estética (lógica da faculdade do conhecimento inferior, filosofia das Graças e das Musas, gnoseologia inferior, arte da beleza do pensar, arte do análogo da razão). (BAUMGARTEN, 1993. § 533. p. 65.)

Tampouco estamos falando unicamente de uma universalização de juízos de gosto. $\mathrm{O}$ conhecimento estético, pela perspectiva fenomenológica, é um conhecimento vinculado à intuição eidética e à consciência imaginativa, que permitem a compreensão de um conhecimento do que é invariável. A experiência fenomenológica da arte, pela perspectiva husserliana, como todas as demais modalidades de experiência, está relacionada com a ideia de necessidade, isto é, com a busca pelo que é indissociável da composição do objeto intencional enquanto objeto estético, mas que é sempre correlato à própria consciência. Será indispensável, em vista disso, que haja uma adequação entre os atos de consciência e o objeto intencional para a efetivação dessa experiência, sendo ela tanto fenomenológica quanto estética.

As equivalências entre as modalidades de experiência fenomenológica e experiência estética são mais explícitas ao partirmos da definição bastante assertiva do que está em jogo na autonomia da estética, isto é,

Uma história da estética é concebível com a condição de dar a este termo um sentido largo: ela seria, por consequência, não a história das teorias e das doutrinas sobre a arte, sobre o belo ou sobre as obras, mas a história da sensibilidade, do imaginário e dos discursos que procuraram valorizar o conhecimento sensível, dito inferior, como contraponto ao privilégio concedido, na civilização ocidental, ao conhecimento racional. (JIMENEZ, 1999, p. 25).

Por meio da aplicação do idealismo transcendental constituinte da fenomenologia husserliana, a análise perceptiva dos dados estéticos é complementada pela análise imaginativa. A experiência estética parte não apenas dos dados sensoriais, mas das entidades suprassensíveis acessadas pela variação imaginativa que segue do método intuitivo fenomenológico. A

${ }^{6}$ Tradução minha (Cf. Saraiva, 1970, p. 35): "l'intention ne peut rien sans une base sensorielle. L' acte surgit de la fusion de ces deux etements, intention et sensation".

LINDENMEYER, Luciane Luísa. Condições filosóficas para uma estética husserliana. Griot : Revista de Filosofia, Amargosa BA, v.21 n.3, p.197-217, outubro, 2021. 
legitimação e o reconhecimento estético daquilo o que se apresenta para o sujeito ocorre ao longo do desenvolvimento intencional da análise estética, tendo como primeiro estágio o contato imediato e perceptivo do objeto, isto é, o momento que corresponde à intenção simples, onde os dados do fenômeno apenas aparecem para a consciência por meio de uma recepção irrefletida, até o momento em que a obra é significativamente intencionada pela consciência através de uma modalidade de exercício imaginativo. Este será o momento de um preenchimento intuitivo do objeto estético.

A experiência estética sempre esteve vinculada, em alguma medida, com as capacidades intuitivas da consciência. Em razão disso, a intuição é facilmente associada à arte como parte da capacidade criativa e mesmo como legitimadora da visão de que o conhecimento artístico não é puramente racional ou empírico, mas dotado de caracteres que não podem sequer serem convertidos para a linguagem. Tanto na experiência estética quanto na experiência fenomenológica estamos diante de um conhecimento de essência que transcende as precondições materiais do objeto intencional.

A percepção imediata da obra de arte enquanto objeto é superada pela variação imaginativa e pelo preenchimento eidético das suas características formais distintas, que determinam as condições ontológicas do objeto enquanto obra de arte. No entanto, é importante destacar que a fenomenologia não visa a explicar a realidade objetiva por meio de uma "ontologização" do mundo circundante. Muito embora, a realidade circundante ou transcendente esteja contida na própria relação de intencionalidade entre consciência e mundo. É nesse sentido que a descrição resultante da análise fenomenológica não deve ser confundida com a dedução, movimento analítico que explica a realidade a partir da universalização conceitual em direção aos objetos particulares. A análise dedutiva está vinculada ao estabelecimento das teorias científicas, enquanto a fenomenologia, ao posicionar-se criticamente em relação à matematização do Lebenswelt, o mundo da vida, abandona simultaneamente qualquer pretensão explicativa dos objetos transcendentais para adotar a posição descritiva dos fenômenos. Assim ficam antepostas as vivências conscientes e há a primazia pela depuração das essências de maneira puramente reflexiva, com base nos preceitos das reduções fenomenológica e eidética.

De maneira bastante semelhante à vivência fenomenológica da consciência, no contexto de uma experiência estética não há a pretensão de esgotar o conteúdo do objeto artístico por meio de uma análise explicativa. A sua efetividade enquanto experiência parte de dados capazes de descrever a obra enquanto objeto intencional, e não objeto puro como já destacado anteriormente. É pela própria relação de intencionalidade, também necessária para a experiência estética, que o conteúdo artístico do objeto deve passar pela consciência transcendental, a qual já é constituída por uma postura descritiva a partir da qual o conteúdo reflexivo apresenta-se não como um dado exclusivo do eu-puro, mas sim como doação de sentido, conforme o movimento de desenvolvimento intencional for realizado. Destarte, podemos considerar uma abordagem husserliana da estética, já que

É próprio, pois, da atitude teórica do filósofo a decisão constante e predeterminada de consagrar toda a sua vida futura à tarefa da teoria, a dar a sua vida um caráter universal, e a construir in finitum conhecimento teórico sobre conhecimento teórico. (HUSSERL, 2008, p. 72).

Estaria o esteta comprometido com essa mesma atitude teórica? Podemos responder afirmativamente ao considerarmos que a estética pretende ser não apenas o campo filosófico de análise da percepção e da sensibilidade, mas que a partir desses preceitos, o esteta pretende assumidamente teorizar sobre as produções artísticas. Essa é a razão pela qual estetas e artistas

LINDENMEYER, Luciane Luísa. Condições filosóficas para uma estética husserliana. Griot : Revista de Filosofia, Amargosa BA, v.21 n.3, p.197-217, outubro, 2021. 
encontram-se em posições conflitantes, mas se aqui partimos das contribuições filosóficas para a reflexão artística, podemos então conjecturar no sentido de que essa é a grande tarefa das reflexões estéticas sobre a arte. A fenomenologia pode contribuir com essa reflexão a partir do estabelecimento do conhecimento eidético acerca desse tipo específico de experiência. No entanto, faz-se necessário considerarmos que o discurso fenomenológico que propõe uma teoria da evidência, de maneira universalizante, pode ser controverso para tratarmos especificamente da experiência estética, uma vez que essa modalidade de experiência parece pressupor uma grande carga de subjetividade, o que não está em questão aqui, isto é, cada indivíduo realiza a sua própria experiência em relação ao conteúdo da obra de arte que lhe é manifesto. É imprescindível que essa dimensão esteja assegurada.

Diante dessas questões, o esforço realizado até aqui foi o de submissão da experiência estética a uma análise propriamente fenomenológica. O seu método específico, o intuitivo, corresponde à análise da relação intencional entre o sujeito e o objeto, considerando especialmente a vivência consciente. Há aqui uma primazia da própria relacionalidade em causa. Algo muito semelhante constitui a experiência estética. Na proposta estética aqui desenvolvida, a relação intencional é a da consciência com a obra de arte, sendo a própria experiência estética uma categoria de consciência intencional, uma vivência fenomenológica que é realizada a partir da intuição eidética, assim como a imaginação também integra o quadro conceitual da fenomenologia husserliana e é de extrema importância para o seu método intuitivo.

A intuição será, portanto, outro elemento comum entre as duas modalidades de experiência analisadas aqui. Como já mencionado, o método intuitivo deve resultar no conhecimento eidético, mas esse conhecimento depende condicionalmente do movimento de retorno às "coisas mesmas", de modo que

[...] elevar as 'ideias lógicas' à claridade e à distinção. Como os conceitos têm que ter sua origem na intuição, e como não são suficientes significações vivificadas apenas por intuições remotas e 'impróprias', é preciso então voltar às 'coisas mesmas' para ter certeza de que o 'dado’ é o mesmo que o “visado’ pelas significações. (MOURA, 1999, p.21).

É justamente esse movimento que deve ser considerado na tentativa de uma efetiva aproximação entre a estética e a fenomenologia, tendo em vista a similaridade entre uma disciplina que pretende teorizar sobre a experiência da arte e outra que pretende estabelecer os parâmetros para os fundamentos do conhecimento seguro. As "coisas mesmas" referidas por Husserl são as essências e não os fatos, desse modo, só é possível tratarmos do que é essencial se partirmos de atos de doação subjetivos, até o momento de retorno aos dados factuais e objetivos que também compõem a experiência.

A experiência fenomenológica é efetivada pelo movimento alternado entre consciência e mundo que é próprio da intencionalidade e da transcendência enquanto condições elementares dos vividos intencionais. Assim, podemos considerar que

Com efeito, a existência da consciência é um absoluto porque a consciência é consciente de si mesma. Ou seja, o tipo de existência da consciência é de ser consciente de si. E ela toma consciência de si enquanto como é consciente de um objeto transcendente. Assim, tudo é claro e lúcido: o objeto encontra-se diante dela com toda a sua opacidade característica, mas ela, ela é pura e simplesmente consciência de ser consciência desse objeto, esta é a lei de sua existência. (SARTRE, 2015, p.23).

É apenas pelo retorno à consciência transcendental, na qual está implicado o transcendente, isto é, que corresponde, no contexto aqui explicitado, à obra de arte e, que é 
analisada por Husserl como um objeto-imagem, percebido sob condições próprias, que a vivência fenomenológica resulta na análise das estruturas intencionais da consciência. Tais estruturas caracterizam a percepção propriamente estética desses objetos, em grande medida, a partir de idealidades ou de uma consciência de imagem que reapresenta os conteúdos originários da percepção imediata. Nesse sentido, tanto a experiência estética quanto a fenomenológica correspondem a análises das manifestações da arte como fenômenos significantes. Utilizando um exemplo devidamente husserliano, podemos compreender o estatuto fenomenológico de um objeto estético. Ao analisar uma gravura de Albrecht Dürer, Husserl (2006, § 111, p. 247) considera que

[...] a consciência perceptiva na qual aparecem, em linhas negras, figuras incolores "cavaleiro a cavalo", "morte" e "diabo". Na observação estética, não nos voltamos não nos voltamos para estes enquanto objetos; estamos voltados para as realidades exibidas "em imagem" ou, mais precisamente, para as realidades "figuradas", o cavaleiro de carne e sangue etc".

Por consequência, essa observação será realizada por meio de uma "consciência de imagem" (HUSSERL, 2006, § 111, p. 247) que opera por "semelhança" (HUSSERL, 2006, § 111, p. 247) com o que é representado pela imagem em questão. A experiência estética dos objetos ocorre por meio de um movimento alternado entre presentificação e re-presentificação ou reapresentação. Ao considerarmos a arte enquanto fenômeno, a experiência estética está em regime de redução transcendental, de maneira que o mundo da obra já está contido na própria subjetividade do sujeito que a contempla. É justamente após a redução fenomenológica que há o reconhecimento concomitante de que o objeto manifesto tem a sua significação originada nos atos intencionais. Isso é o fenômeno: o objeto intencional é dado na subjetividade transcendental e é reconhecido pela consciência. No caso dos objetos-imagem, encontramos uma modificação do processo intencional de modo que,

A imagem como objeto de imagem que aparece de tal e tal maneira através das cores e formas determinadas, daí não o objeto representado, o sujeito da imagem, mas o análogo da imagem da fantasia. Por uma questão de distinção, podemos diferenciar terminologicamente: a reapresentação ou representação do objeto de imagem e o objeto de imagem reapresentado ou representado ${ }^{7}$. (HUSSERL, 1980, § 1, p. 109).

A análise husserliana acerca da clarificação dos conceitos lógicos recorre aos processos mentais que originam os diferentes conjuntos de objetos que correspondem às essências de sua condição. Assim, só podemos falar de essência no âmbito da reflexão racional dos fenômenos puros. É justamente por conta dessa análise lógica que fundamenta, em grande medida, a fenomenologia husserliana, que a estética fenomenológica, para a qual tentamos apresentar aqui as suas bases filosóficas, é considerada por alguns autores como sendo uma modalidade da estética lógica, porque

A Estética chamada lógica pretende ser um meio-termo, uma conciliação entre a Estética filosófica e a empirista. Por um lado, pretende fazer um estudo o mais rigoroso possível dos fatos estéticos, como preconiza a Estética empirista; por outro lado, como a Estética

\footnotetext{
7 Tradução minha (Cf. HUSSERL, 1980, § 1, p. 109): "Das Bild als durch die bestimmte Farben- und Formengebung so und so erscheinendes Bildobjekt, also nicht das abgebildete Objekt, das Bildsujet, sondern das Analogon des Phantasiebildes. Wir können der Deutlichkeit halber terminologisch unterscheiden: das repräsentierende oder abbildende und das repräsentierte oder abgebildete Bildobjekt. Von beiden ist wieder unterschieden das physische Bild. Die schlichte Rede vom Bilde ist aber zweideutig, sofern neben dem physischen Bilde auch das repräsentierende Bildobjekt als Bild".
} 
filosófica, pretende atingir a essência dos dados que formam o objeto do seu estudo. (SUASSUNA, 2008, p. 391).

A estética fenomenológica realiza a análise dos objetos estéticos com base no mesmo paradigma intuitivo proposto pela teoria husserliana de estabelecimento de uma lógica pura, a partir da reflexão sobre as origens fenomenológicas dos conceitos. $O$ conceito é justamente o elemento que converte os fenômenos em conhecimento. Conhecimento que, para a fenomenologia, é sempre eidético, visto que sua análise não pretende explicar os objetos, mas sim analisar as evidências fenomenológicas enquanto modos de atos de consciência. Nesse sentido, a fenomenologia distancia-se, igualmente, da própria ontologia, como já esboçado, em razão de que essa última incorre em uma modalidade de análise explicativa, estando ainda claramente vinculada aos objetos puros. Pelo contrário, a fenomenologia husserliana não visa exclusivamente ao desvelamento do ser dos fenômenos manifestos, mas sim pretende analisar o movimento de retorno à consciência transcendental, ou mesmo, às "coisas mesmas", que apenas podem ser consideradas na perspectiva consciente proposta na sua abordagem intuitiva.

Como consequência da análise intuitiva dos fenômenos, a experiência estética é justamente o instante em que ocorre a efetividade da reflexão propriamente intencional, isto é, há experiência estética no momento do preenchimento eidético da consciência pelo objeto intencional. No contexto da análise lógica de Husserl, é nesse instante da intencionalidade que ocorre a clarificação conceitual com base na correlação entre fenômeno e consciência. $O$ processo que resulta na origem dos fenômenos está diretamente ligado ao exame aprofundado deste correlato, de modo que o que deve permanecer não é o dado objetivo e tampouco o fato psíquico, mas sim o objeto ideal que provém da própria correlação entre objeto e consciência. É apenas a partir da tomada da fenomenologia como análise das correlações intencionais enquanto objetos ideais é que o seu método intuitivo é plenamente caracterizado em relação às propostas metodológicas indutiva e dedutiva.

A experiência estética é revertida em experiência fenomenológica na medida em que na sua efetividade está a clarificação conceitual pautada pelo acesso ao conteúdo ideal do objeto artístico e não o esgotamento explicativo do conteúdo da obra de arte. Nesse sentido, a experiência estética, pela perspectiva fenomenológica, realiza-se enquanto experiência descritiva, na medida em que o processo de preenchimento da essência do objeto artístico enquanto manifestação fenomênica acontecer para a consciência.

A experiência estética, enquanto experiência fenomenológica, realiza-se como vivência intuitiva da obra de arte. $O$ momento de preenchimento do conteúdo estético depende diretamente da condição de aprioridade da própria intuição enquanto elemento constituinte da racionalidade e como ato intencional significante. A partir do momento de preenchimento da intuição pelo fenômeno do aparecimento do objeto artístico a realização da experiência estética ocorre como conhecimento imanente, indubitavelmente presente na interioridade da consciência. Nesse sentido, a experiência estética, aqui apresentada como sendo equivalente à experiência fenomenológica, não corresponde unicamente a uma experiência de efetividade de significação baseada no esforço de clarificação conceitual da obra enquanto objeto lógico, como caracterizado por Suassuna anteriormente. Esse procedimento de análise está comprometido com o próprio movimento de reflexão racional relacionado com a consciência pública fenomenológica, de maneira que a experiência estética não é, aqui, puramente conceitual, mas converte-se em vivência da obra enquanto ela mesma, isto é, na sua condição de ipseidade, enquanto objeto propriamente estético. 
A consciência pública que constitui esta análise está diretamente comprometida com o estabelecimento de um modelo de investigação que encontra nas próprias capacidades intuitivas e imaginativas da consciência os seus componentes condutores até a fundação do conhecimento eidético. Ou ainda, das condições necessárias para que a modalidade de relação intencional que caracteriza a experiência estética da obra de arte permita a análise descritiva dessa própria relação intencional, a qual resultará no estabelecimento da estrutura própria da experiência estética. Portanto, é no contexto da intencionalidade, da experiência de consciência com o objeto estético, que acontece a vivência descritiva.

Se o elemento que impera na experiência fenomenológica e que determina a sua análise característica é a própria vivência consciente, na sua constituição de intencionalidade, o esforço fenomenológico está situado, antes de qualquer outro preceito, no entendimento de qual modalidade intencional permitirá a descrição mais adequada para que o objeto estético tenha legitimidade enquanto tal. Essa descrição específica ocorre através da consciência de imagem e da consciência imaginativa que atuaram como atos modificadores da percepção. É assim que podemos compreender em que medida apreendemos o conhecimento de essência do objeto representado em detrimento da exclusividade da percepção simples e direta do objeto estético ou objeto-imagem que se apresenta no primeiro momento do desenvolvimento intencional.

Por outro lado, a crítica husserliana à concepção de representação mental deve ser cuidadosamente considerada, uma vez que ela corrobora com a refutação de que a fenomenologia seria, no fim das contas, uma teoria idealista, no sentido de que essa concepção recebeu em sistemas filosóficos que a precederam na linha histórica filosófica, como na teoria hegeliana e demais vertentes do idealismo alemão. Isso significa que a visão teórica de que a fenomenologia visa à ideia que fundamenta os conceitos não quer dizer que os objetos ideais correspondam apenas a representações mentais, mas sim que as ideias equivalem ao eidos, às essências dos objetos enquanto fenômenos. Afinal,

\begin{abstract}
Se a fenomenologia introduz o lema intencional - "toda consciência é consciência de algo" - com um sentido polêmico, esse sentido estará, antes de tudo, na recusa implícita que a intencionalidade traz da assimilação de toda consciência perceptiva a uma consciência de imagem ou de signo, quer dizer, na recusa do conceito clássico de representação. Esse conceito, enquanto explicação da relação entre a subjetividade e a transcendência, pode ser resumido na doutrina segundo a qual "fora" está a coisa, e na consciência uma imagem que a representa (LUIIQ/1,421). Entre a subjetividade e a transcendência existiria um terceiro termo, a ideia quadro, encarregada de estabelecer a mediação. (MOURA, 1989, p.77).
\end{abstract}

Assim, as ideias que são intuídas pela consciência e que correspondem ao conhecimento eidético das coisas não são apenas representações isoladas e presentes unicamente na mente. A ideia é parte indissociável do próprio objeto, não sendo ela um novo elemento resultante da experiência entre consciência e mundo. Desse modo, o objeto estético é, em grande medida, tomado não como uma simples representação unicamente mental, mas já como aparecimento do objeto eidético, isto é, sem qualquer apelo ao psicologismo. Essa proposta é parte da pretensão husserliana de estabelecer os pré-requisitos para a objetividade fenomenológica. É através dessa objetividade que é possível o conhecimento eidético. Nesse sentido, a objetividade fenomenológica deve ser considerada a partir dos atos de consciência que constituem o caráter intencional da experiência fenomenológica.

O rigor da fenomenologia husserliana voltado para o estabelecimento das propriedades objetivas está mesmo na análise dos fenômenos como aparecimentos de maneira descritiva com base no desenvolvimento intencional vinculado à intuição. Sendo assim, 
[...] Não é por si mesmo que um conteúdo testemunha ser imagem de outro. Como na representação por imagem nós visamos o objeto sob o fundamento da imagem que aparece, deve-se perguntar como se sabe que a consciência se refere a um objeto estranho através de um conteúdo dado como sua imagem. Ora, como ser imagem não é um predicado real, esse saber exige que se tenha previamente a experiência da coisa. (MOURA, 1989, p. 78).

$O$ forte apelo idealista da fenomenologia husserliana, assim como o seu perfil rigorosamente abstrativo e mesmo hermético indicaria grandes dificuldades de transposição das suas proposições, inicialmente voltadas para o pensamento lógico, para as reflexões sobre a experiência estética, esta que é fundamentada de maneira mais aceitável pelo uso de princípios vinculados à experiência sensível que está implícita na análise estética. Nesse sentido, faz-se necessário o destaque para o que está no cerne da experiência estética sob a perspectiva da inspeção fenomenológica, em termos husserlianos, qual seja, a própria experiência consciente e os seus modos de efetivação enquanto vivência fenomenológica. No entanto, essa experiência, por estar previamente associada ao conhecimento eidético, será convertida em uma experiência que apresenta como resultado elementos públicos. É a partir dessa especificidade que a importância da intuição eidética e da consciência imaginativa para o exame fenomenológico torna-se reconhecível.

\section{Considerações finais}

Considerar a experiência estética como experiência fenomenológica ou transcendental é considerar a sua estrutura de consciência característica, ou ainda, a estrutura intencional que possibilita a íntima vinculação entre o sujeito e o objeto estético. O que está em jogo, diante das condições específicas da fenomenologia, bem como no cerne da experiência estética é a própria vivência consciente realizada diante do objeto estético que é sempre, nesse contexto, um objeto correlato, sem que ele possa ser dissociado da consciência. A intencionalidade ocorre por meio da alternância entre o eu empírico, efetivado pelo momento inicial, o perceptivo, e o eu transcendental, por meio do qual é realizado o instante de retorno à consciência. Neste último, podemos contar com os atos imaginativos. A análise fenomenológica não visa apenas ao desvelamento do ser das coisas, porque o conhecimento eidético é resultante da própria vivência fenomenológica, de modo que

Embora a fenomenologia nos peça para nos concentrarmos em nossa experiência, em sobre como as coisas "aparecem" para nós, a permanecemos fiéis ao caráter dessa experiência, não devemos negligenciar ou distorcer a ideia de que tais "aparições" são principalmente aparições de coisas. (CERBONE, 2012, p.13).

Sob essas condições, apresentamos a pertinência da fenomenologia para a reflexão da experiência estética a partir de duas principais dimensões. Primeiramente, pela análise intencional que caracteriza especificamente a experiência estética. E, nesse sentido, três elementos fenomenológicos mostram-se como centrais para a experiência estética, a saber, a intuição, a percepção e a imaginação. E no segundo momento, para além da relacionalidade entre consciência e objeto estético, o rigor metodológico da fenomenologia permite acessarmos, inclusive, a experiência estética como um momento privilegiado para o estabelecimento de conhecimentos eidéticos. Seja por questões existenciais significativas, seja pelas condições da estrutura para uma consciência do objeto propriamente estético. Pensamos, assim, em traçar as possibilidades teóricas 
instituídas já na fenomenologia originária de Husserl para a efetivação de uma estética fenomenológica que foi aprofundada posteriormente ao seu pensamento.

A proposta de um exame fenomenológico do mundo transcendente, da realidade externa à consciência, viabiliza a aplicação de conceitos importantes do pensamento husserliano para reflexionarmos as condições prévias de desenvolvimento da estética fenomenológica efetivada por pensadores sucessores de Husserl, que se consagraram no desenvolvimento de conceitos próprios e importantes sobre questões específicas do pensamento estético. Tomemos como exemplo, a distinção realizada no interior do projeto teórico de Mikel Dufrenne acerca da obra de arte e do objeto especificamente estético, isto é, não há uma correlação prévia entre esses dois conceitos. Uma obra de arte não é, necessariamente, um objeto estético, assim como o contrário prevalece. Por conseguinte, uma obra de arte pode não ser percebida esteticamente, assim como um objeto estético pode corresponder mesmo a um objeto natural.

No entanto, ainda não contávamos com essas especificações conceituais no contexto teórico originário da fenomenologia para uma abordagem estética do projeto husserliano. A não ser as suas considerações sobre a consciência imaginativa e a consciência de imagem vinculadas à percepção estética e sobre as suas considerações sobre os objetos-imagem. Ainda assim, ao tratar não de um objeto estético, mas de uma consciência estética, a sua fenomenologia foi projetada para responder aos problemas específicos da lógica, de maneira intimamente vinculada ao estabelecimento também de uma teoria do conhecimento.

De todo modo, existem diversos indicativos conceituais já na abordagem husserliana bastante intuitivos para o desenvolvimento de uma aplicação dos preceitos fenomenológicos para algumas questões específicas da estética. Dentre elas, como objetivo temático desse artigo, a abordagem comparativa entre a experiência estética e a vivência fenomenológica, primeiramente, em razão da predeterminação intencional que constitui as duas modalidades de experiência mencionadas. Em nenhum dos casos podemos dissociar o sujeito do objeto de análise, e, por conseguinte, a clara crítica husserliana à matematização da vida fortaleceu a instauração filosófica de uma modalidade de conhecimento comprometido com a objetividade e a universalidade e não redutível à empiria.

Suas proposições apresentam uma abertura investigativa para que a relação intencional constituinte da experiência estética corresponda a uma experiência filosófica e transcendental não redutível à explicação objetiva do conteúdo sensorial da obra e, tampouco, coincida com uma descrição unicamente subjetiva, visto que, como já mencionado, é a própria vivência intencional que está sob análise, a partir da intuição e da imaginação. Portanto,

[...] o útil, o agradável, o amável, o verdadeiro, o bem. Todos esses respondem a modos específicos da intencionalidade e o conjunto talvez cubra o campo das relações fundamentais do objeto com o sujeito. Cada um desses valores, incomparáveis entre si, circunscreve um domínio próprio, ordenado para uma exigência que diz respeito, ao mesmo tempo, ao objeto e ao sujeito. (DUFRENNE, 2002, p. 52).

É através do desenvolvimento intencional da experiência estética que há a passagem da percepção imediata do objeto para o estabelecimento de uma consciência de imagem, a partir da qual é realizada a reflexão propriamente intuitiva dos fenômenos estéticos. Essa é uma noção importante para a modalidade de intencionalidade que deve ser analisada quando o objeto intencional, aqui, o objeto estético, for uma imagem representativa de outro objeto. A imagem, como objeto que representa outro objeto, encontra-se, em princípio, numa posição metafísica de inferioridade em relação aos demais objetos. Embora ela mesma seja igualmente um objeto físico, justamente em razão da sua condição de representação ou de presentificação de conteúdos que 
transcendem a própria materialidade do objeto imagem. Nessa conformidade, "Presentificar é tornar presente, repetindo uma presença originária", (ARAÚJO, 2011, p. 260), de maneira que essa presença originária da percepção é reapresentada sob as condições imanentes da consciência, dentre as quais está a sua própria temporalidade. Os atos imaginativos são regidos pelo tempo interno da consciência, uma vez que a imaginação apresenta conteúdos não atuais, não correspondentes ao tempo objetivo da realidade sensível.

O modelo idealista transcendental instaurado pela fenomenologia husserliana incorre na adoção de uma concepção de subjetividade bastante peculiar, já que ela contém em si mesma o mundo circundante, o qual está apenas suspenso no momento da análise descritiva. Destarte, a subjetividade transcendental não conta exclusivamente com a análise sensível, em razão de que após a redução fenomenológica ou a neutralização da realidade, a subjetividade transcendental realiza a reflexão acerca dos fenômenos, de sorte que

Quando a Fenomenologia tem tematicamente objetos de consciência, seja de que tipo for, tanto reais como ideais, ela tem-nos, então, apenas como objetos dos respectivos modos de consciência; a descrição que pretende captar o fenômeno pleno e concreto das cogitationes deve olhar constantemente para trás, indo do lado objetivo ao lado da consciência, e procurar as correspondências que aqui continuamente se verificam. (HUSSERL, 2013, p. 14).

Esse movimento dos atos de consciência voltados para o transcendente e do retorno à consciência transcendental encontra espaço privilegiado na experiência estética, em diversos níveis contidos no próprio desenvolvimento intencional da consciência, no qual a percepção é apenas uma das dimensões de investigação fenomênica. A vivência consciente dos fenômenos se realiza também pela reflexão imaginativa. Assim,

É da essência geral da apreensão eidética intuitiva imediata que ela possa ser efetuada [...] com base na mera presentificação de individualidades exemplares. No entanto, como acabamos de mostrar, a presentificação, por exemplo, a imaginação pode ser tão perfeitamente clara que possibilita apreensões e evidências eidéticas perfeitas. (HUSSERL, 2006. § 70. p. 152).

O movimento de desenvolvimento intencional referente à intuição eidética está diretamente vinculado à consciência propriamente imaginativa. Essa modalidade de consciência é melhor compreendida na medida em que Husserl trata da importância do exercício imaginativo. Assim como a hermenêutica filosófica gadameriana, influenciada em grande medida pela fenomenologia husserliana, possibilitou a aplicação de suas proposições no campo dos objetos de arte, diferentemente da hermenêutica clássica, por conta da importância da experiência estética enquanto paradigma de experiência de verdade. Husserl já havia atribuído à ficção a mesma relevância enquanto modelo mais adequado para a superação do discurso científico e da sua vocação naturalista e objetificadora. $O$ conceito de ficção está intimamente vinculado, na fenomenologia de Husserl, à intuição e à consciência imaginativa como ato de consciência privilegiado no que se refere ao acesso aos fenômenos.

Sob as condições desenvolvidas aqui, a experiência estética acontece, em nível fenomenológico, a partir da alternância entre as presentificações realizadas pela imaginação e pela consciência de imagem, com as quais são modificados os conteúdos já apreendidos sensitivamente. Uma estética fenomenológica especificamente husserliana estará comprometida com a consciência de imagem e com a imaginação. Com isso, os atos de imaginação permitem o reconhecimento dos vividos de consciência. A experiência estética apresenta semelhanças com a experiência

LINDENMEYER, Luciane Luísa. Condições filosóficas para uma estética husserliana. Griot : Revista de Filosofia, Amargosa BA, v.21 n.3, p.197-217, outubro, 2021. 
fenomenológica, em razão da sua própria orientação, isto é, os objetos percebidos esteticamente estão situados no horizonte fenomenológico, de maneira que a efetividade da vivência estética de seu conteúdo só é possível através das condições intencionais ou de íntima relação entre sujeito e objeto.

A modalidade de objeto que está no cerne da análise fenomenológica é justamente a dos objetos correlatos, ou seja, aqueles que são indissociáveis da análise imanente de sua significação ou sentido. Uma das condições para que os objetos sejam percebidos esteticamente é a sua própria dimensão de significação transcendental e através do retorno intencional aos modos de doação dos objetos. Assim, em nível transcendental, a imaginação possibilita a reapresentação dos conteúdos apreendidos sensitivamente, com base na consciência de imagem retida por meio do conhecimento de essência. 


\section{Referências}

ARAÚJO, Joaquim Carlos. Estudos Husserlianos de Maria Manuela Saraiva. In: Phainomenon, n. 22-23, Lisboa, 2011, p. 249-274.

BAUMGARTEN, Alexander. Estética, a lógica da arte e do poema. Trad. Míriam Sutter Medeiros. Petrópolis, RJ: Vozes, 1993.

CERBONE, David R. Fenomenologia. Edição digital. Tradução de Caesar Souza. Petrópolis, RJ: Editora Vozes, 2012. Livro eletrônico.

DUFRENNE, Mikel. Estética e Filosofia. Trad. Roberto Figurelli. $3^{a}$ edição. São Paulo: Editora Perspectiva, 2002.

DUFRENNE. The phenomenology of Aesthetic Experience. Translated by Edward S. Casey. Evaston: Northwestern University Press, 1973.

GADAMER, Hans Georg. Verdade e Método: traços fundamentais de uma hermenêutica filosófica. Trad. Flávio Paulo Meurer. $1^{\text {a }}$ Edição. Petrópolis: Editora Vozes, 1997.

HEIDEGGER, Martin. A origem da obra de arte. Trad. Maria da Conceição Costa. Lisboa: Edições $70,1977$.

HEIDEGGER, Martin. Os problemas fundamentais da fenomenologia. Trad. Marco Antônio Casanova. Petrópolis, RJ: Vozes, 2012.

HUSSERL, Edmund. A crise da humanidade europeia e a Filosofia. Trad. Urbano Zilles. 3. ${ }^{a}$ Ed. Porto Alegre: EDIPUCRS, 2008.

HUSSERL, Edmund. Ideias para uma fenomenologia pura e para uma filosofia fenomenológica: introdução geral à fenomenologia pura. Trad. Márcio Suzuki. Aparecida SP: Ideias e letras, 2006. HUSSERL, Edmund. Lições para uma fenomenologia da consciência interna do tempo. De acordo com o texto da Husserliana X. Trad. Pedro M. S. Alves. Lisboa: Imprensa Nacional - Casa da Moeda, 1994.

HUSSERL, Edmund. Meditações Cartesianas e Conferências de Paris. De acordo com o texto de Husserliana I; editado por Stephan Strasser; traduzido por Pedro M. S. Alves. Rio de Janeiro: Forense Universitária, 2003.

HUSSERL, Edmund. Phantasie, Bildbewusstsein, Erinnerung: zur Phänomenologie der anschaulichen Vergegenwärtigungen. Texte aus dem Nachlass (1898-1925). Hua XXIII. Hrsg. von E. Marbach. The Hague: Nijhoff, 1980.

JIMENEZ, Marc. O que é estética. Trad. Fulvia M. L. Moretto. São Leopoldo: Editora Unisinos, 1999.

MOURA, Carlos Alberto Ribeiro de. Crítica da razão na fenomenologia. São Paulo: Nova Stella: Editora da Universidade de São Paulo. 1989.

ROSENFIELD, Kathrin H. Estética. $2^{a}$ Ed. Edição digital. Rio de Janeiro: Editora Zahar, 2006. SAES, Sílvia Faustino de Assis. Percepção e imaginação. $1^{a}$ Ed. São Paulo: Editora WMF Martins Fontes, 2010.

SARAIVA, Maria Manuela. L’imagination selon Husserl. The Hague, Netherlands: Martinus Nijhoff, 1970.

SARTRE, Jean-Paul. A transcendência do ego: esboço de uma descrição fenomenológica. Trad. João Batista Kreuch. Petrópolis, RJ: Vozes, 2015.

SARTRE, Jean-Paul. Esboço para uma teoria das emoções. Trad. Paulo Neves. Porto Alegre: L\&PM, 2009.

SERRA, Alice Mara. Imagem e suporte: Fenomenologia e desconstrução. Ekstasis: revista de fenomenologia e hermenêutica. V.3. N.1, p. 25-42. 2014. Disponível em: < https://www.e-

LINDENMEYER, Luciane Luísa. Condições filosóficas para uma estética husserliana. Griot : Revista de Filosofia, Amargosa BA, v.21 n.3, p.197-217, outubro, 2021. 
publicacoes.uerj.br/index.php/Ekstasis/article/view/12790 > Acesso em 20 de Abril de 2021. http://dx.doi.org/10.12957/ek.2014.12790 .

SUASSUNA, Ariano. Iniciação à estética. Rio de Janeiro: José Olympio, 2008.

Autor(a) para correspondência / Corresponding author: Luciane Luisa Lindenmeyer. lucianelindenmeyer@gmail.com 